\title{
Effect of the ACY-1 gene on HER2 and TRAIL expression in rectal carcinoma
}

\author{
ZIZHONG XU ${ }^{1}$, YATING $\mathrm{HU}^{2}$ and ZHAOHUI YU ${ }^{3}$ \\ Departments of ${ }^{1}$ General Surgery, ${ }^{2}$ Endocrinology and ${ }^{3}$ Anorectal, \\ The First People's Hospital Xianyang City, Xianyang, Shanxi 712000, P.R. China
}

Received December 8, 2018; Accepted November 5, 2019

DOI: $10.3892 /$ etm.2021.10249

\begin{abstract}
The incidence of rectal carcinoma (RC) is increasing and the age at onset of the disease is reducing. Therefore, elucidating the pathogenesis of $\mathrm{RC}$ is beneficial for early diagnosis and improving the prognosis. Aminoacylase-1 (ACY-1) is abnormally expressed in various malignant tumor tissues. Furthermore, the human epidermal grow th factor receptor-2 (HER2) gene is involved in tumor metastasis and invasion, while tumor necrosis factor-related apoptosis-inducing ligand (TRAIL) induces tumor cell apoptosis. The aim of the present study was to investigate the effect of the ACY-1 gene on the expression of HER2 and TRAIL in RC. Cancerous and adjacent tissues from RC patients were collected. ACY-1 expression was analyzed by immunohistochemistry. The rectal cancer cell lines HT29 and SW620, and normal colorectal mucosal epithelial fetal human cells were cultured in vitro. ACY-1 gene and protein expression levels were tested by reverse transcription-quantitative PCR and western blotting. ACY-1 small interfering RNA (siRNA) was transfected into HT29 and SW620 cells. Cell proliferation was detected by thiazolyl blue MTT assay. Caspase- 3 activity was assessed using a commercial kit. HER2 and TRAIL expression levels were determined by western blotting. ACY-1 expression was significantly increased in cancer tissue compared with adjacent tissue $(\mathrm{P}<0.05)$. ACY-1 expression was elevated in HT29 and SW620 cells compared with normal colorectal mucosal epithelial cells $(\mathrm{P}<0.05)$. ACY-1 siRNA transfected into HT29 cells downregulated its expression, inhibited cell proliferation, enhanced caspase-3 activity, reduced HER 2 expression and upregulated TRAIL expression $(\mathrm{P}<0.05)$. ACY-1 expression was found to be increased in rectal cancer tissue. Therefore, targeting the ACY-1 gene may regulate HER 2 and TRAIL expression levels, and may reduce the occurrence and inhibit the development of rectal cancer.
\end{abstract}

Correspondence to: Dr Zhaohui Yu, Department of Anorectal, The First People's Hospital Xianyang City, 10 Biyuan Road, Xianyang, Shanxi 712000, P.R. China

E-mail: zhifuyongzhuang@126.com

Key words: rectal carcinoma, aminocyclase-1, human epidermal growth factor receptor-2, apoptosis, proliferation

\section{Introduction}

Rectal carcinoma (RC) is a common intestinal malignant tumor belonging to the colorectal cancer class. RC is ranked third and fourth worldwide in terms of global tumor morbidity and mortality, respectively, with an increasing overall prevalence and a trend towards an earlier onset of disease $(1,2)$. With the improvement of living conditions, constant changes in diet structure and lifestyle, and the accelerated pace of work, there has been an increased intake of high-fat, high-protein and low-fiber foods, resulting in dietary disorders (3). RC has become the second most prevalent malignant tumor of the digestive tract behind by gastric cancer $(4,5)$. Diagnosis of RC is limited by the unclear early symptoms; therefore, diagnosis and treatment of RC are usually delayed, and most patients have already reached advanced stages at the time of diagnosis (6). The 5-year survival rate of RC is relatively low (7). The pathogenesis of $\mathrm{RC}$ has not been fully elucidated as it involves multiple factors, processes and genes $(8,9)$. Understanding the pathogenesis behind $\mathrm{RC}$ is essential to develop early diagnosis procedures and to improve the prognosis, thus a greater understanding of $\mathrm{RC}$ pathogenesis is key to improving the survival rate and quality of life of patients.

Aminoacylase-1 (ACY-1) is a zinc-binding enzyme that hydrolyzes $\mathrm{N}$-acetyl amino acids into free amino acids and acetic acid, and is expressed at abnormally high levels in various malignant tumor tissues. It has been shown that ACY-1 is overexpressed in liver cancer and that ACY-1 expression is associated with tumor proliferation, invasion and metastasis $(10,11)$. Human epidermal growth factor receptor-2 (HER2) is a proto-oncogene which is expressed in healthy adults, but its expression increases in more than one-third of tumors (12). HER 2 can promote cell proliferation by inhibiting apoptosis, enhancing tumor cell invasiveness, promoting tumor angiogenesis and lymphangiogenesis and promoting tumor occurrence and development (13). In particular, HER2 gene overexpression is closely associated with breast cancer and can be used for clinical monitoring and indicating prognosis (14). Tumor necrosis factor (TNF)-related apoptosis-inducing ligand (TRAIL) is a newly discovered member of the TNF family (15) and can rapidly promote large-scale apoptosis in transformed cells, virus-infected cells and tumor cells $(16,17)$. Therefore, the aim of the present study was to investigate the 
effect of the ACY-1 gene on HER2 and TRAIL expression in $\mathrm{RC}$.

\section{Materials and methods}

Research objective. A total of $48 \mathrm{RC}$ patients, who had received surgery in the First People's Hospital Xianyang City between May and December 2017, were enrolled for the present study. This included 26 males and 22 females with an average age of $55.8 \pm 7.9$ (range, 41-75) years. There were 18 cases of mucinous adenocarcinoma, 20 cases of papillary adenocarcinoma, and 10 cases of signet ring cell carcinoma. The inclusion criteria were as follows (6): First time treatment with no adjuvant therapy such as chemotherapy, radiotherapy or biological therapy prior to the surgery. The exclusion criteria were as follows (6): Previous severe heart, lung, liver or kidney failure; cerebrovascular disease; other malignant tumor types; autoimmune diseases; infectious diseases; unable to cooperate with the study; and incomplete clinical data. The study was approved by the Medical Ethics Committee of The First People's Hospital Xianyang City, and the patients or their families had signed informed consent forms. Specimens were collected of intraoperative rectal cancer and adjacent tissue (at least $3 \mathrm{~cm}$ from tumor tissue), and stored in liquid nitrogen. Some samples were prepared with $4 \%$ neutral formalin solution at $4^{\circ} \mathrm{C}$ for $15 \mathrm{~min}$ for immunohistochemistry.

Main reagents and instruments. The rectal cancer cell lines HT29 and SW620 were purchased from the American Type Culture Collection and the authenticity was verified by Suzhou Genetic Testing Biotechnology Co., Ltd. These cell lines, as well as the normal colorectal mucosal epithelial fetal human cell line (American Type Culture Collection) were cryopreserved by our laboratory. DMEM, EDTA, FBS, penicillin and streptomycin were purchased from HyClone; GE Healthcare Life Sciences. DMSO and MTT powder were purchased from Gibco; Thermo Fisher Scientific, Inc. Trypsin was purchased from Sigma-Aldrich; Merck KGaA. The PVDF membrane was purchased from Pall Life Sciences. All western blotting-related chemical reagents were purchased from Beyotime Institute of Biotechnology. ECL reagents were purchased from GE Healthcare. Rabbit anti-human HER2 monoclonal antibody, rabbit anti-human TRAIL monoclonal antibody, rabbit anti-human ACY-1 monoclonal antibody, and mouse anti-rabbit horseradish peroxidase (HRP)-conjugated IgG secondary antibody were purchased from Cell Signaling Technology, Inc. The immunohistochemical streptavidin-perosidase kit (cat. no. SA1098) was purchased from Boster Biological Technology. The RNA extraction kit and the reverse transcription kit were purchased from Axygen; Corning Inc. The caspase-3 activity assay kit (cat. no. 556485) was purchased from BD Biosciences. The Labsystem Version 1.3.1 microplate reader was purchased from Bio-Rad Laboratories, Inc. The ABI 7900 HT Real-time PCR machine was purchased from Applied Biosystems; Thermo Fisher Scientific, Inc. Other commonly used reagents were purchased from Sangon Biotech Co., Ltd.

Immunohistochemistry. Tissue samples were prepared and sectioned to a thickness of $5 \mu \mathrm{m}$. Paraffin sections were immunohistochemically stained using the SP kit following the
Table I. Primer sequences.

\begin{tabular}{lll}
\hline Gene & \multicolumn{1}{c}{ Forward (5'-3') } & \multicolumn{1}{c}{ Reverse $\left(5^{\prime}-3^{\prime}\right)$} \\
\hline GAPDH & ACCAGGTATCTTGG & TAACCATGTCAGC \\
& TTG & GTGGT \\
ACY-1 & AGTCGACCACTCC & GATTCTGTGGTCA \\
& ACAGT & CTATATT \\
\hline
\end{tabular}

ACY-1, aminoacyclase-1.

Table II. ACY-1 expression in RC and adjuvant tissue.

\begin{tabular}{lrrc}
\hline & \multicolumn{3}{c}{ ACY-1 } \\
\cline { 2 - 4 } Tissue type & $(-)$ & $(+$ or ++$)$ & Positive rate $(\%)$ \\
\hline Adjacent tissue & 42 & 4 & 8.33 \\
RC & 2 & 46 & $95.83^{\mathrm{a}}$
\end{tabular}

${ }^{\mathrm{a}} \mathrm{P}<0.05$ vs. adjuvant tissue group. ACY-1, aminoacyclase-1; RC, rectal carcinoma.

manufacturer's instructions. After blocking with $10 \%$ normal FBS at room temperature for $30 \mathrm{~min}$ to block endogenous peroxidase, the sections were incubated with ACY-1 monoclonal antibodies $(1: 1,000)$ at $37^{\circ} \mathrm{C}$ for $1 \mathrm{~h}$. Washing was performed with PBS solution three times, and the sections were incubated with biotinylated goat anti-mouse IgG secondary antibodies (cat. no.ab6788; Abcam; 11,000) at room temperature for $20 \mathrm{~min}$. Next, the sections were incubated with streptavidin-biotin complex to amplify the signal at room temperature for $20 \mathrm{~min}$. After 3,3'-diaminobenzidine staining, the sections were counterstained with hematoxylin for $1 \mathrm{~min}$ at room temperature, dehydrated with serial gradients of ethanol, and sealed. The sections were then visualized using a light microscope (magnification, $x 400$ ). Positive expression was determined by the number of cells that contained brown/yellow granules. Samples that contained no brown/yellow stained cells were defined as negative, samples with $<50 \%$ of cells stained brown/yellow in five random field were defined as positive $(+)$ and when $\geq 50 \%$ of cells were stained brown-yellow, samples were defined as strong positive $(++)$.

Cell culture and grouping. Cells were resuspended in $1 \mathrm{ml}$ fresh DMEM and topped up with $4 \mathrm{ml}$ of fresh DMEM at $37^{\circ} \mathrm{C}$ and $5 \% \mathrm{CO}_{2}$ prior to seeding. Cells were seeded in 6-well plates at $1 \times 10^{5}$ cells $/ \mathrm{cm}^{2}$ in high-glucose DMEM (containing $10 \% \mathrm{FBS}, 100 \mathrm{U} / \mathrm{ml}$ penicillin and $100 \mu \mathrm{g} / \mathrm{ml}$ streptomycin) at $37^{\circ} \mathrm{C}$ with $5 \% \mathrm{CO}_{2}$. The cells in the 3 rd-8th generation and logarithmic growth phase were used for experiments. HT29 cells were randomly divided into three group: A control group; a small interfering RNA (siRNA) (Sigma-Aldrich; Merck KGaA) negative control group (scramble group); and an ACY-1 siRNA (Sigma-Aldrich; Merck KGaA) group.

Liposomal transfection. ACY-1 siRNA was transfected into HT29 or SW620 cells. The ACY-1 siRNA sequence was as 

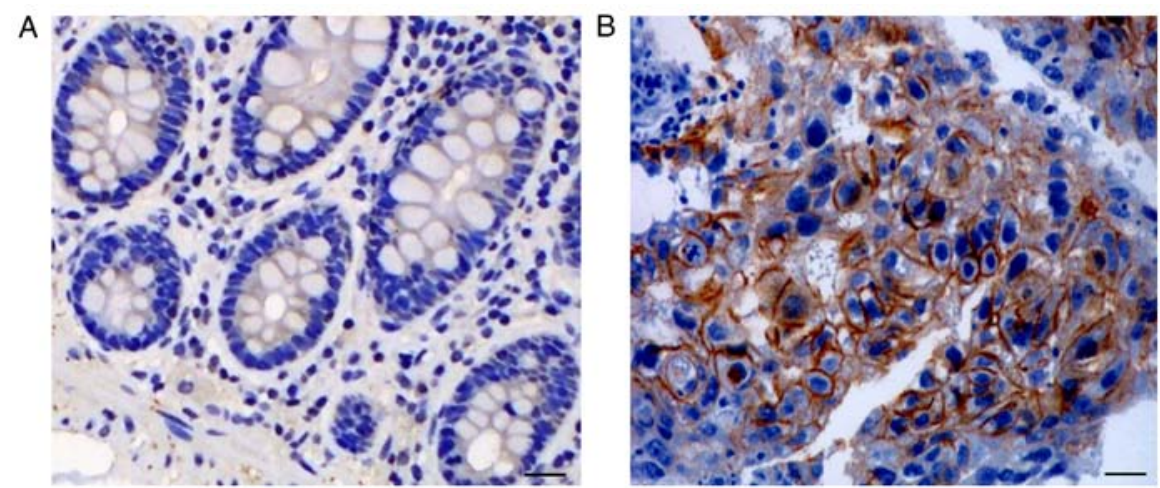

Figure 1. ACY-1 expression in RC tissue and adjacent tissue (magnification, $\mathrm{x} 400$ ). (A) ACY-1 expression in adjacent tissue. (B) ACY-1 expression in RC. Scale bars, $10 \mu \mathrm{m}$. ACY-1, aminoacyclase-1; RC, rectal carcinoma.

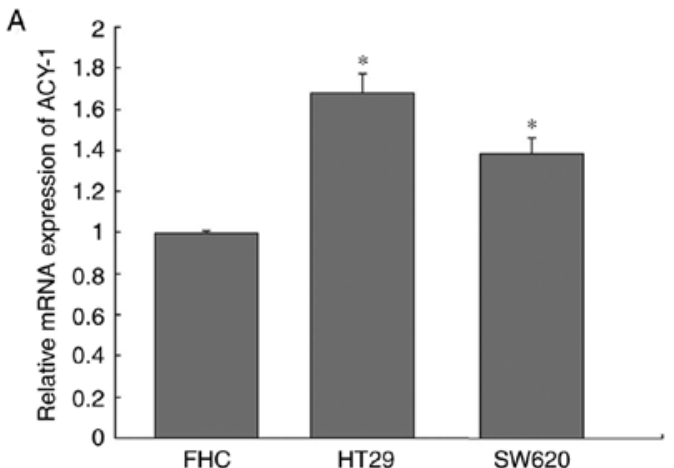

B
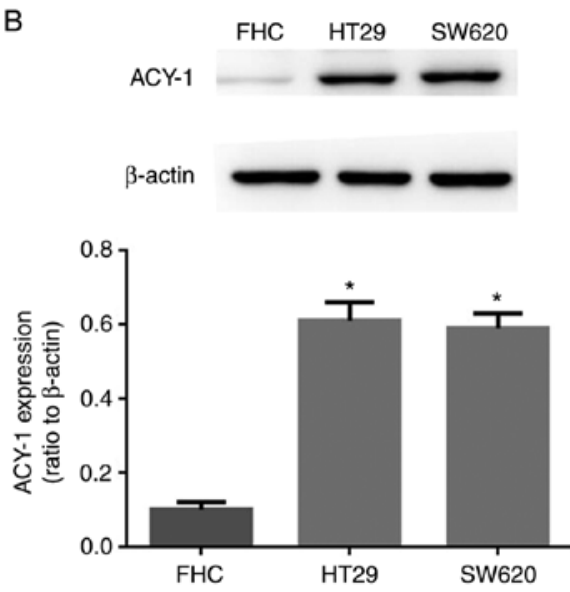

Figure 2. ACY-1 expression in rectal carcinoma cell lines. (A) ACY-1 gene expression in HT29, SW620 and FHC cells. (B) ACY-1 protein expression in HT29, SW620 cells and FHC cells. "P<0.05 vs. FHC. ACY-1, aminoacyclase-1; FHC, fetal human cells.

follows: Forward, 5'-GATAAATGGACTTGGAGAACAG-3' and reverse, 5'-TAGACATGGAGACTTGACAGACT-3'. The siRNA negative control primer sequence was: Forward, 5'-ATT CACCTGCCATGTAT-3' and reverse, 5'-GAACACTAATGT TGACAG-3'. Cells were grown to $70-80 \%$ confluence. The ACY-1 siRNA or negative control siRNA was added to $200 \mu \mathrm{l}$ of serum-free DMEM medium and mixed at room temperature for 15 min. The Lipofectamine ${ }^{\circledR} 2000$ (Thermo Fisher Scientific, Inc.) was mixed with $20 \mathrm{nM}$ ACY-1 siRNA or negative control siRNA and incubated for $30 \mathrm{~min}$ at room temperature. The mixture together with $1.6 \mathrm{ml}$ serum-free DMEM, was incubated with the cells at $37^{\circ} \mathrm{C}$ with $5 \% \mathrm{CO}_{2}$ for $6 \mathrm{~h}$. The cell culture medium was replaced with DMEM containing serum and cultured for $48 \mathrm{~h}$ before experimental research.

Reverse transcription-quantitative PCR (RT-qPCR). Total RNA was extracted from tissues or cells using TRIzol ${ }^{\circledR}$ reagent and reverse-transcribed to cDNA using High Capacity cDNA Reverse Transcription Kit (Thermo Fisher Scientific, Inc.), according to the manufacturer's instructions $\left(25^{\circ} \mathrm{C}\right.$ for $10 \mathrm{~min}$, $37^{\circ} \mathrm{C} 120$ for $\mathrm{min}$ and at $85^{\circ} \mathrm{C}$ for $5 \mathrm{~min}$ ). The primers were designed by Primer Premier 6.0 software (Premier Biosoft) and synthesized by Invitrogen; Thermo Fisher Scientific, Inc. (Table I). The qPCR reaction was performed using Fast SYBR Green Master Mix (Thermo Fisher Scientific, Inc.) with 35 cycles of $92^{\circ} \mathrm{C}$ for $30 \mathrm{sec}, 58^{\circ} \mathrm{C}$ for $45 \mathrm{sec}$ and $72^{\circ} \mathrm{C}$ for $35 \mathrm{sec}$. GAPDH was used as a reference gene. The relative expression was calculated using the $2^{\Delta \Delta \mathrm{Cq}}$ method (18).

MTT assay. HT29 and SW620 cells in the logarithmic growth phase were trypsinized and seeded onto a 96-well plate at 3,000 cells/well. The cells were randomly divided into the control group, scramble group and ACY-1 siRNA group, with three replicates per group. After treatment, the cells were given $20 \mu \mathrm{l}$ of $5 \mathrm{~g} / \mathrm{l}$ MTT solution for $4 \mathrm{~h}$ in the incubator. Next, $150 \mu \mathrm{l}$ DMSO/well was applied and the solution was shaken for $10 \mathrm{~min}$. After the purple crystals were fully dissolved, the absorbance (A) was measured at $570 \mathrm{~nm}$ to calculate cell viability rate. Cell viability rate was calculated with the following formula: Cell viability rate=sample A value/control A value $x 100 \%$. The experiment was repeated three times $(n=3)$.

Caspase-3 activity detection. The cells were trypsinized and centrifuged at $4^{\circ} \mathrm{C}$ at $600 \mathrm{x}$ g for $5 \mathrm{~min}$. Next, the cells were lysed with cell lysis buffer [10 mM Tris- $\mathrm{HCl} ; 10 \mathrm{mM}$ $\mathrm{NaH}_{2} \mathrm{PO}_{4} / \mathrm{NaHPO}_{4}$ (pH 7.5); $130 \mathrm{mM} \mathrm{NaCl} ; 1 \%$ Triton X-100; $10 \mathrm{mM}$ sodium pyrophosphate] on ice for $15 \mathrm{~min}$ and centrifuged at $4^{\circ} \mathrm{C}$ and $20,000 \times \mathrm{g}$ for $5 \mathrm{~min}$. Subsequently, $2 \mathrm{mM}$ Ac-DEVD-AMC (included in the caspase-3 activity kit) was added, the optical density (OD) was measured at $450 \mathrm{~nm}$ to calculate the caspase- 3 activity.

Western blot analysis. Cells were treated with RIPA buffer (150 mM NaCl, $1 \%$ NP-40, 0.1\% SDS, $2 \mu \mathrm{g} / \mathrm{ml}$ Aprotinin, $2 \mu \mathrm{g} / \mathrm{ml}$ Leupeptin, $1 \mathrm{mM}$ PMSF, $1.5 \mathrm{mM}$ EDTA, and $1 \mathrm{mM}$ 

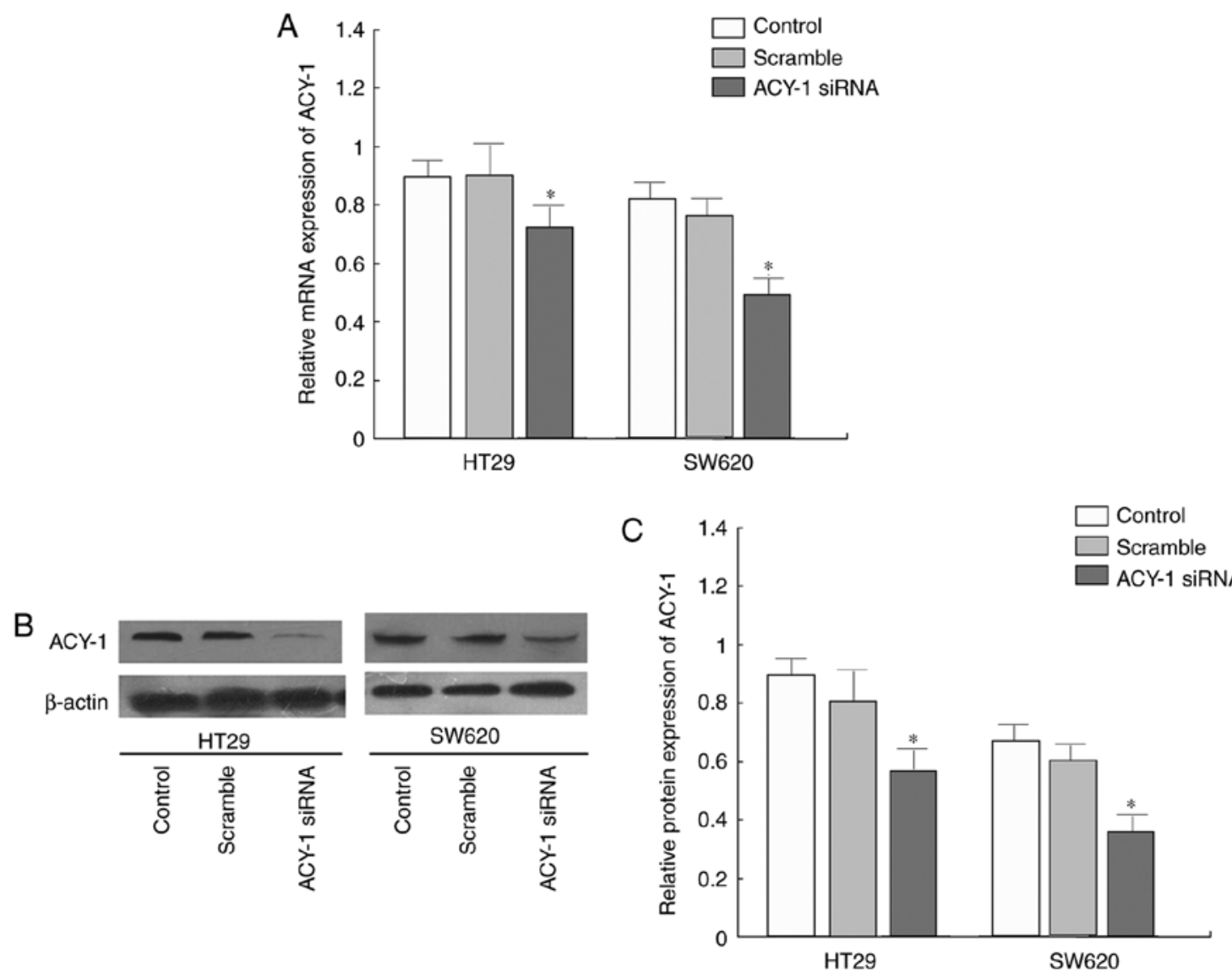

Figure 3. Impact of ACY-1 siRNA on ACY-1 mRNA and protein expression in HT29 and SW620 cells. (A) ACY-1 gene expression in HT29 or SW620 cells. (B) ACY-1 protein expression in TH29 or SW620 cells. (C) ACY-1 protein expression analysis. " $\mathrm{P}<0.05$ vs. retrospective control. ACY-1, aminoacyclase-1; siRNA, small interfering RNA.

sodium vanadate) and quantified by BCA assay. In total, $40 \mu \mathrm{g}$ of protein was electrophoresed using $10 \%$ SDS-PAGE. The gel was transferred to a PVDF membrane by semi-dry transfer at $150 \mathrm{~mA}$ for $1.5 \mathrm{~h}$. After blocking with $5 \%$ skim milk at room temperature for $1 \mathrm{~h}$, the membrane was incubated with ACY-1, HER2, TRAIL and $\beta$-actin primary antibodies $(1: 1,000,1: 2,000 ; 1: 1,500$ and $1: 1,000$, respectively) at $4^{\circ} \mathrm{C}$ overnight. The membranes were then incubated with goat anti-rabbit secondary antibodies $(1: 2,000)$ in the dark for $30 \mathrm{~min}$ at room temperature. The labelled membrane was imaged using chemiluminescence reagent for $1 \mathrm{~min}$ and analyzed by image processing system software and Quantity one software (version 4.52; Bio-Rad Laboratories, Inc.). $\beta$-actin was used as a loading control. The experiment was repeated four times $(n=4)$.

Statistical analysis. All data analyses were performed using SPSS 19.0 software (IBM Corp.). The measurement data are presented as the mean \pm SD and compared by one-way ANOVAs with post hoc LSD tests. The enumeration data are depicted as percentages and were compared by $\chi^{2}$ test. $\mathrm{P}<0.05$ was considered to indicate a statistically significant difference.

\section{Results}

IHC analysis of ACY-1 expression in RC tissue and adjuvant tissue. Immunohistochemistry was used to detect ACY-1 expression in RC and adjacent tissue. ACY-1 expression was significantly increased in rectal cancer tumor tissue, with positive staining in the cell membrane and cytoplasm. However, the adjacent tissue presented negative for ACY-1 expression (-) $(\mathrm{P}<0.05)$ (Fig. 1; Table II).

ACY-1 expression in RC cell lines. ACY-1 gene and protein expression levels were measured between rectal cancer HT29 or SW620 cells and normal colorectal mucosal epithelial cells. It was found that ACY-1 gene and protein expression levels were upregulated in HT29 and SW620 cells compared with control cells ( $\mathrm{P}<0.05$; Fig. 2).

Impact of ACY-1 siRNA on ACY-1 mRNA and protein expression in HT29 cells. The effect of siRNA on ACY-1 mRNA and protein expression levels was detected by RT-qPCR. The gene and protein expression levels of ACY-1 were significantly reduced after siRNA treatment $(\mathrm{P}<0.05$; Fig. 3$)$.

Influence of ACY-1 siRNA on HT29 cell proliferation. The effect of ACY-1 siRNA on the proliferation of HT29 or SW620 cells was detected using MTT assays. siRNA transfection significantly inhibited HT29 or SW620 cell proliferation compared with control transfection ( $\mathrm{P}<0.05$; Fig. 4).

Effect of ACY-1 siRNA on caspase-3 activity in HT29 cells. The effect of ACY-1 siRNA on the activity of caspase- 3 in 


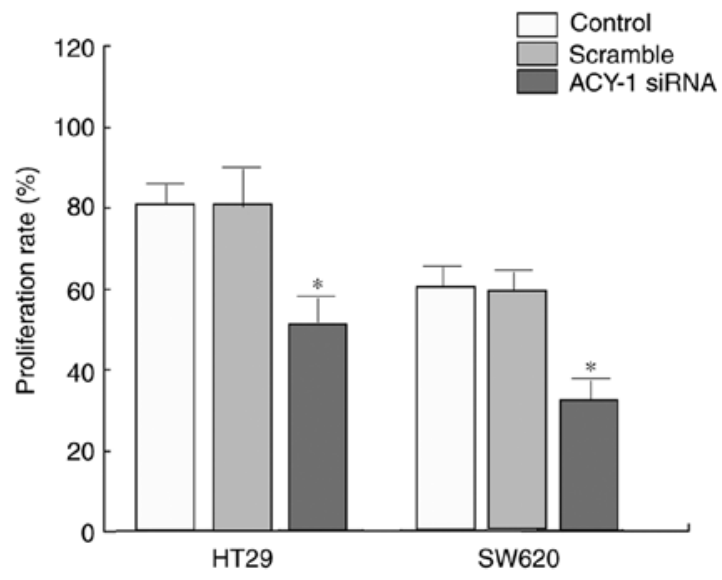

Figure 4. Influence of ACY-1 siRNA on HT29 and SW620 cell proliferation. ${ }^{*} \mathrm{P}<0.05$ vs. respective control. ACY-1, aminoacyclase-1; siRNA, small interfering RNA.

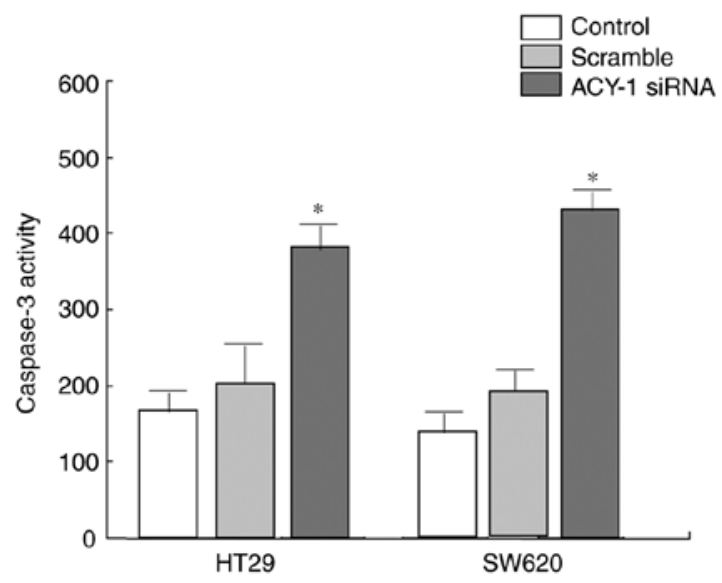

Figure 5. Effect of ACY-1 siRNA on caspase-3 activity in HT29 and SW620 cells. " $\mathrm{P}<0.05$ vs. respective control. ACY-1, aminoacyclase-1; siRNA, small interfering RNA.

HT29 or SW620 cells was detected using the caspase-3 activity kit. It was revealed that siRNA significantly enhanced caspase-3 activity in HT29 or SW620 cells compared with control treatment $(\mathrm{P}<0.05$; Fig. 5).

Impact of ACY-1 siRNA on HER2 expression in HT29 cells. Western blotting was performed to analyze the effect of ACY-1 siRNA on HER2 expression in HT29 or SW620 cells. It was demonstrated that siRNA against ACY-1 significantly suppressed HER 2 expression compared with the control group $(\mathrm{P}<0.05$; Fig. 6).

Influence of ACY-1 siRNA on TRAIL expression in HT29 cells. Western blotting was performed to analyze the effect of ACY-1 siRNA on TRAIL expression in HT29 or SW620 cells. ACY-1 siRNA significantly increased TRAIL expression compared with the control group $(\mathrm{P}<0.05$; Fig. 7).

\section{Discussion}

A previous study has investigated the expression profile of ACY-1 in renal transplantation and as an indicator of

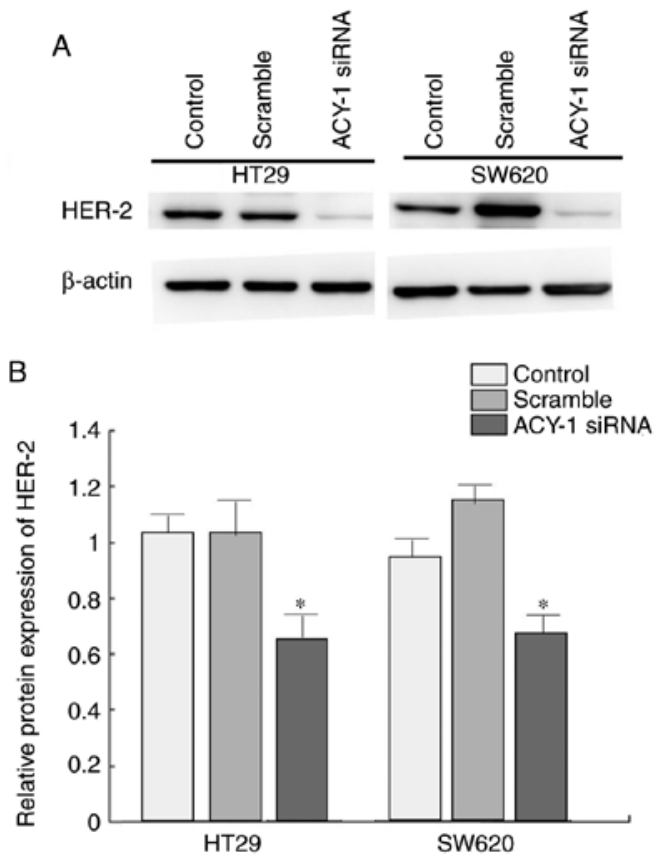

Figure 6. Impact of ACY-1 siRNA on HER2 expression in HT29 or SW620 cells. (A) The impact of ACY-1 siRNA on HER2 protein expression. (B) Semi-quantitative analysis of HER 2 protein expression. " $\mathrm{P}<0.05$ vs respective control. ACY-1, aminoacyclase-1; HER2, human epidermal growth factor receptor-2; siRNA, small interfering RNA.

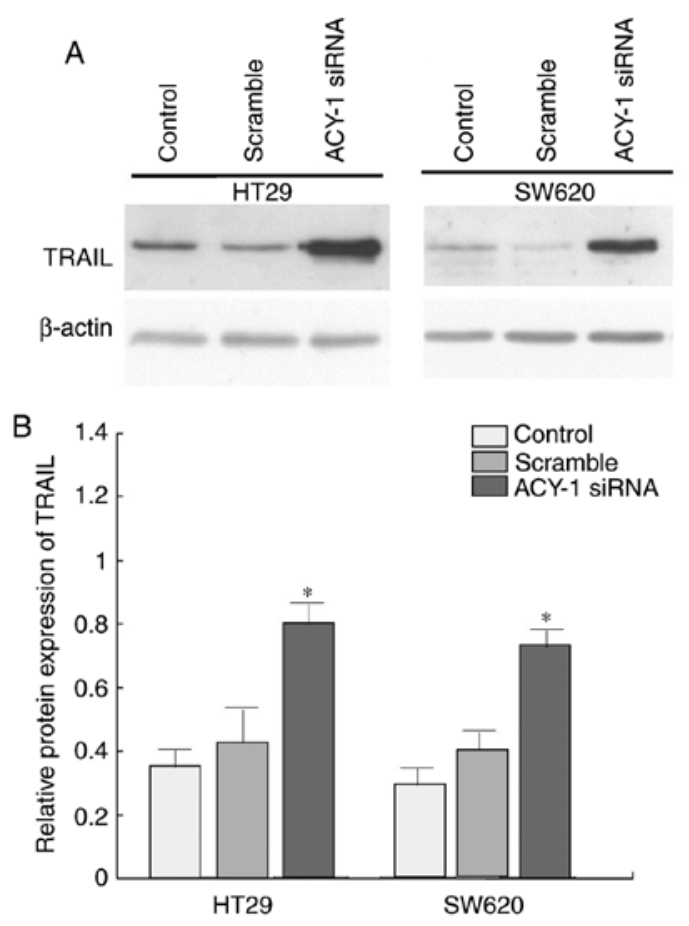

Figure 7. Influence of ACY-1 siRNA on TRAIL expression in HT29 or SW620 cells.(A) the impact of ACY-1 siRNA on TRAIL protein expression. (B) Semi-quantitative analysis of TRAIL protein expression. " $\mathrm{P}<0.05$ vs. respective control. ACY-1, aminoacyclase-1; siRNA, small interfering RNA; TRAIL, tumor necrosis factor-related apoptosis-inducing ligand.

prognosis (19). As one of the acylated amino acid active enzymes, ACY-1 is mainly expressed in the cell membrane and cytoplasm. It can acetylate $\alpha$-acylated amino acids and enhance protein stability in cells (20). There are relatively few 
studies on the role of ACY-1 in tumors. It has been previously found that ACY-1 expression is decreased in liver cancer and renal cell carcinoma (21-23); however, the expression of ACY-1 in rectal cancer has not been clarified. In the present study, ACY-1 expression was shown to be significantly increased in rectal cancer tissues and cells, suggesting that it may be associated with the occurrence and development of rectal cancer.

The proto-oncogene HER2, also known as the neu gene or the c-erbB-2 gene, is involved in several physiological processes, such as cell proliferation and differentiation (24). However, under the influence of external factors, the HER2 gene is abnormally expressed, which may lead to the abnormal activation of its related protein product P185, inducing tumorigenesis and metastasis (25). TRAIL is an apoptosis-inducing ligand; the binding of TRAIL to its receptor promotes the caspase-3 protease cascade and induces apoptosis (26). The present study demonstrated that ACY-1 siRNA decreased the expression of ACY-1 at the gene and protein level, which significantly downregulated the expression levels of HER2, elevated TRAIL expression, suppressed cell proliferation and upregulated caspase-3 activity in HT29 and SW620 cells. This indicates that ACY-1 siRNA in rectal cancer may enhance TRAIL expression by inhibiting HER 2 expression, thereby inhibiting tumor cell proliferation and promoting tumor cell apoptosis. In further research, it is necessary to explore the specific target and related mechanisms of ACY-1, and provide relevant evidence for its use in the clinical diagnosis and treatment of RC.

In conclusion ACY-1 expression is increased in rectal cancer tissue. Targeting the ACY-1 gene can regulate the expression of both HER2 and TRAIL which may inhibit the occurrence and development of rectal cancer.

\section{Acknowledgements}

Not applicable.

\section{Funding}

No funding was received.

\section{Availability of data and materials}

All data generated or analyzed during this study are included in this published article.

\section{Authors' contributions}

$\mathrm{ZX}$ and YH performed the experiments and analyzed the data. ZY designed the study and wrote the manuscript.

\section{Ethics approval and consent to participate}

The current study was approved by The First People's Hospital Xianyang City and consent was obtained for participation.

\section{Patient consent for publication}

Not applicable.

\section{Competing interests}

The authors declare that they have no competing interests.

\section{References}

1. Pratap Singh A, Kumar A, Dhar A, Agarwal S and Bhimaniya S: Advanced colorectal carcinoma with testicular metastasis in an adolescent: A case report. J Med Case Rep 12: 304, 2018.

2. Hu YH, Wei JW, Chang H, Xiao WW, Lin JZ, Cai MY, Cai PQ, Kong LH, Chen G, Pan ZZ, et al: The high pCR rate of sandwich neoadjuvant treatment in locally advanced rectal cancer may translate into a better long-term survival benefit: 5 -year outcome of a Phase II clinical trial. Cancer Manag Res 10: 4363-4369, 2018.

3. Hu FB: Globalization of diabetes: The role of diet, lifestyle, and genes. Diabetes Care 34: 1249-1257, 2011.

4. Guedj N, Maggiori L, Pote N, Norkowski E, Cros J, Bedossa P and Panis Y: Distal intramural and tumor spread in the mesorectum after neoadjuvant radiochemotherapy in rectal cancer: About 124 consecutive patients. Hum Pathol 52: 164-172, 2016.

5. Pedziwiatr M, Pisarska M, Kisielewski M, Major P, Mydlowska A, Rubinkiewicz M, Winiarski M and Budzynski A: ERAS protocol in laparoscopic surgery for colonic versus rectal carcinoma: Are there differences in short-term outcomes? Med Oncol 33: 56, 2016.

6. Kong I, Vorunganti S, Patel M, Farrell T, Timotin E, Quinlan-Davidson S, Pond G, Sur R and Hunter R: Prospective comparison of rectal dose reduction during intracavitary brachytherapy for cervical cancer using three rectal retraction techniques. Brachytherapy 15: 450-455, 2016.

7. Yu E, DiPetrillo TA, Ramey S and Leonard KL: Comparison of endorectal ultrasound versus pelvic magnetic resonance imaging for radiation treatment planning in locally advanced rectal cancer. Pract Radiat Oncol 5: e451-e455, 2015.

8. Hernández J, Molins L, Fibla JJ, Heras F, Embún R and Rivas JJ; Grupo Español de Metástasis Pulmonares de Carcinoma Colo-Rectal (GECMP-CCR) de la Sociedad Española de Neumología y Cirugía Torácica (SEPAR): Role of major resection in pulmonary metastasectomy for colorectal cancer in the Spanish prospective multicenter study (GECMP-CCR). Ann Oncol 27: 850-855, 2016.

9. Simkens GA, van Oudheusden TR, Braam HJ, Wiezer MJ, Nienhuijs SW, Rutten HJ, van Ramshorst B and de Hingh IH: Cytoreductive surgery and HIPEC offers similar outcomes in patients with rectal peritoneal metastases compared to colon cancer patients: A matched case control study. J Surg Oncol 113: 548-553, 2016.

10. Balamurugan TS, Huang $\mathrm{CH}$, Chang $\mathrm{PC}$ and Huang ST: Electrochemical molecular switch for the selective profiling of cysteine in live cells and whole blood and for the quantification of aminoacylase-1. Anal Chem 90: 12631-12638, 2018.

11. Caira S, Iannelli A, Sciarrillo R, Picariello G, Renzone G, Scaloni A and Addeo P: Differential representation of liver proteins in obese human subjects suggests novel biomarkers and promising targets for drug development in obesity. J Enzyme Inhib Med Chem 32: 672-682, 2017.

12. Meyer HJ, Gundermann P, Hohn AK, Hamerla G and Surov A: Associations between whole tumor histogram analysis parameters derived from ADC maps and expression of EGFR, VEGF, Hif 1-alpha, Her-2 and Histone 3 in uterine cervical cancer. Magn Reson Imaging 57: 68-74, 2019.

13. Schizas D: Should addition of five years of ovarian suppression to tamoxifen be 'must' for hormone receptor positive and HER-2 positive breast cancer under the age of 35? J BUON 23: 1201, 2018.

14. Tabak SA, Khalifa SE and Fathy Y: HER-2 immunohistochemical expression in bone sarcomas: A new hope for osteosarcoma patients. Open Access Maced J Med Sci 6: 1555-1560, 2018.

15. Radke DI, Ling Q, Hasler R, Alp G, Ungefroren H and Trauzold A: Downregulation of TRAIL-receptor 1 increases TGF $\beta$ type II receptor expression and TGF $\beta$ signalling via microRNA-370-3p in pancreatic cancer cells. Cancers (Basel) 10: E399, 2018.

16. Wang Z, Zhang M, Lv X, Fan J, Zhang J, Sun J and Shen Y: GroEL/ES mediated the in vivo recovery of TRAIL inclusion bodies in Escherichia coli. Sci Rep 8: 15766, 2018.

17. Byun HS, Zhou W, Park I, Kang K, Lee SR, Piao X, Park JB, Kwon TK, Na M and Hur GM: C-27-carboxylated oleanane triterpenoids up-regulate TRAIL DISC assembly via p38 MAPK and CHOP-mediated DR5 expression in human glioblastoma cells. Biochem Pharmacol 158: 243-260, 2018. 
18. Livak KJ and Schmittgen TD: Analysis of relative gene expression data using real-time quantitative PCR and the 2(-Delta Delta C(T)) method. Methods 25: 402-408, 2001.

19. He X, Hong Y, Wang X, Zhang X, Long J, Li H, Zhang B, Chen S, Liu Q, Li H, et al: Identification and clinical significance of an elevated level of serum aminoacylase-1 autoantibody in patients with hepatitis B virus-related liver cirrhosis. Mol Med Rep 14: 4255-4262, 2016.

20. Ali S and Sheerin NS: Biomarkers of acute injury: Predicting the long-term outcome after transplantation. Kidney Int 84: 1072-1074, 2013.

21. Wei X, Li J, Xie H, Ling Q, Wang J, Lu D, Zhou L, Xu X and Zheng S: Proteomics-based identification of the tumor suppressor role of aminoacylase 1 in hepatocellular carcinoma. Cancer Lett 351: 117-125, 2014

22. Welberry Smith MP, Zougman A, Cairns DA, Wilson M, Wind T, Wood SL, Thompson D, Messenger MP, Mooney A, Selby PJ, et al: Serum aminoacylase-1 is a novel biomarker with potential prognostic utility for long-term outcome in patients with delayed graft function following renal transplantation. Kidney Int 84: 1214-1225, 2013.
23. Zhong Y, Onuki J, Yamasaki T, Ogawa O, Akatsuka S and Toyokuni S: Genome-wide analysis identifies a tumor suppressor role for aminoacylase 1 in iron-induced rat renal cell carcinoma. Carcinogenesis 30: 158-164, 2009.

24. Iqbal $\mathrm{N}$ and Iqbal $\mathrm{N}$ : Human epidermal growth factor receptor 2 (HER2) in cancers: Overexpression and therapeutic implications. Mol Biol Int 2014: 852748, 2014.

25. Yang M, Fang X, Li J, Xu D, Xiao Q, Yu S, Hu H, Weng S, Ding K and Yuan Y: Afatinib treatment for her-2 amplified metastatic colorectal cancer based on patient-derived xenograft models and next generation sequencing. Cancer Biol Ther 20: 391-396, 2019.

26. Choi SA, Lee C, Kwak PA, Park CK, Wang KC, Phi JH, Lee JY, Chong S and Kim SK: Histone deacetylase inhibitor panobinostat potentiates the anti-cancer effects of mesenchymal stem cell-based sTRAIL gene therapy against malignant glioma. Cancer Lett 442: 161-169, 2019.

This work is licensed under a Creative Commons Attribution-NonCommercial-NoDerivatives 4.0 International (CC BY-NC-ND 4.0) License. 